\title{
Predictors of the Overlap Syndrome and Its Association with Comorbidities in Patients with Chronic Obstructive Pulmonary Disease
}

\author{
Esther Helen Steveling ${ }^{a} \quad$ Christian F. Clarenbach ${ }^{b}$ David Miedinger ${ }^{a}$ \\ Claudia Enz ${ }^{a}$ Selina Dürr ${ }^{a, c}$ Sabrina Maier ${ }^{a, c}$ Noriane Sievi ${ }^{b}$ Stefanie Zogg ${ }^{a, c}$ \\ Jörg D. Leuppi ${ }^{\mathrm{a}, \mathrm{c}}$ Malcolm Kohler ${ }^{\mathrm{b}}$ \\ ${ }^{a}$ Clinic of Internal Medicine, University Hospital Basel, Basel, bSleep Disorders Center and Division of Pulmonology, \\ University Hospital Zurich, Zurich, ' $M e d i c a l$ University Clinic of Baselland in Liestal and Medical Faculty of Basel, \\ Liestal/Basel, Switzerland
}

\section{Key Words}

Chronic obstructive pulmonary disease $\cdot$ Obstructive sleep apnea $\cdot$ Overlap syndrome

\begin{abstract}
Background: The occurrence of both chronic obstructive pulmonary disease (COPD) and obstructive sleep apnea (OSA) in an individual patient has been described as 'overlap syndrome', which has been associated with poor prognosis. Little is known about the possible predictors of the overlap syndrome and its association with comorbidities contributing to impaired outcome. Objectives: This study aimed to evaluate the prevalence and possible predictors of the overlap syndrome and its association with comorbidities in a cohort of COPD patients. Methods: Individuals with COPD (GOLD stages I-IV, risk groups A-D) were recruited from outpatient clinics. Information on age, gender, body mass index (BMI), smoking status, Epworth sleepiness scale (ESS), COPD assessment test, comorbidities, medications and exacerbations in the past year was collected and a spirometry was performed. Participants underwent a nocturnal polygraphy using the ApneaLink ${ }^{\mathrm{TM}}$ device at home. An apnea-hypopnea index $(\mathrm{AHI})>10$ per hour was considered to indicate OSA.
\end{abstract}

Results: We enrolled 177 COPD patients (112 men) with a mean age of 64 years (range 42-90), of whom 35 (20\%) had an ESS score above 10. During nocturnal polygraphy, 33 patients (19\%) had evidence of OSA. In multivariate analysis, $\mathrm{BMI}$ and pack years were positively associated with $\mathrm{AHI}$, independent of other significant $\mathrm{AHI}$ determinants from univariate analysis. Arterial hypertension and diabetes were more common in patients with the overlap syndrome. Conclusions: Almost $20 \%$ of COPD patients also have OSA. BMI and smoking history seem to be predictors of the overlap syndrome, and these patients may be more often affected by hypertension and diabetes.

(c) 2014 S. Karger AG, Basel

\section{Introduction}

Chronic obstructive pulmonary disease (COPD) is a chronic inflammatory response of the airways and lungs to noxious particles and gases and is usually progressive [1]. Comorbidities, such as cardiovascular disease, play an important role regarding the morbidity and mortality in COPD [2]. The combination of both COPD and obstructive sleep apnea (OSA) has been described as the

\section{KARGER}

E-Mail karger@karger.com

www.karger.com/res
(C) 2014 S. Karger AG, Basel

0025-7931/14/0886-0451\$39.50/0
Dr. Esther Steveling

SAF Building, 2nd floor, South Kensington Campus

Imperial College London, Allergy and Clinical Immunology

London SW7 2AZ (UK)

E-Mail esthersteveling@gmail.com 
'overlap syndrome' $[3,4]$. OSA is characterized by repetitive episodes of upper airway collapse leading to apnea and hypopnea associated with intrathoracic pressure swings, intermittent hypoxia and arousals from sleep with consecutive activation of the sympathetic nervous system [5]. There is conflicting data about the prevalence and the predictors of the overlap syndrome. The prevalence of COPD and OSA in the middle-aged Western population has been estimated to be as high as $19[6,7]$ and $30 \%[8,9]$, respectively. The prevalence of the overlap syndrome seems to vary between 11 and $41 \%$, dependent on the population studied [10-13].

The coexistence of both diseases in an individual patient may be associated with poor outcome as patients with the overlap syndrome seem to have a higher mortality than patients with either COPD or OSA alone [14]. An adequate treatment may reduce the rate of hospitalisations and deaths [14]. However, despite the poor outcome there is still little data on the clinical presentation of patients with the overlap syndrome and associated comorbidities, thus more information is needed in order to identify and treat such patients at an early stage. The aim of this study was the evaluation of the prevalence and possible predictors of OSA in a typical cohort of COPD patients, and to further identify associated comorbidities which may contribute to the high risk of mortality in patients with the overlap syndrome.

\section{Material and Methods}

Subjects

This study was conducted at the University Hospitals in Basel and Zurich, Switzerland. Patients between 42 and 90 years of age with objectively confirmed COPD according to the Global Initiative for Chronic Obstructive Lung Disease (GOLD) guidelines were consecutively included in this study [1]. We excluded subjects with upper or lower respiratory tract infections and an exacerbation of COPD within the most recent 6 weeks. All patients signed informed consent and the study was approved by the ethical committee 'Beider Basel' (EK-163/11) and the ethical committee of the University Hospital of Zurich (EK1734).

\section{Study Design}

In this cross-sectional, two-center study, subjects performed a spirometry and were accordingly categorized in COPD GOLD stages I-IV. In a clinical examination, height, weight, body mass index (BMI) and blood pressure were measured. Smoking history and exacerbation rate in the most recent 12 months, comorbidities and medications were recorded during a structured physician-led interview. Participants completed the Epworth sleepiness scale (ESS) and the COPD assessment test (CAT). Patients were asked to perform an unattended sleep study at home with the Apnea-
Link $^{\mathrm{TM}}$ (ResMed, MAP Medicine Technology, Martinsried, Germany) device during one night. Examinations took place between July 2011 and January 2012.

Methods

Spirometry

The degree of airflow limitation was assessed by performing both spirometry and COPD staging according to published guidelines [15].

Exacerbation Frequency

An exacerbation was defined as a sustained worsening of the patient's condition from the stable state and beyond normal dayto-day variations that was acute at onset and might have warranted additional treatment, such as antibiotics and/or steroids. Subjects were asked about the number of exacerbations in the most recent 12 months [16].

Epworth Sleepiness Scale

The ESS is a self-administered item to assess sleep propensity during normal daily activities. The German version of the questionnaire was used in this study [17]. Clinically relevant daytime sleepiness was assumed if individuals had a score of greater than 10.

\section{COPD Assessment Test}

The CAT is a self-assessed questionnaire in which patients have to rate eight COPD-related symptoms, on a scale from 0 (impact low) to 5 (impact very high). It is used to assess the impact of COPD on an individual's quality of life and has been proven to be reliable, repeatable and sensitive for variations in disease severity [18].

Sleep Studies

Home sleep studies were performed using the ApneaLink device. The device records the patient's nasal respiratory pressure signal and finger oximetry during sleep, and has been validated as an accurate instrument with which to detect snoring, apnea-hypopnea and oxygen desaturations [19]. The results of the sleep study were scored automatically with dedicated software and manual review to ensure the accuracy of the data. Apneas were defined as a cessation of airflow lasting more than $10 \mathrm{~s}$ and hypopneas as a reduction in airflow of at least $30 \%$ lasting more than $10 \mathrm{~s}$, associated with a drop in oxygen saturation of $>4 \%$ [19]. An apnea-hypopnea index $(\mathrm{AHI})$ of $>10$ events per hour was considered to indicate the presence of OSA.

Analysis

Data were analyzed using SPSS version 19 and STATA 12 (StataCorp, College Station, Tex., USA). Data are presented as median (quartiles) and mean (standard deviation, SD), unless otherwise stated. Descriptive data analysis was performed and value distribution was analyzed with the Shapiro-Wilk normality test. Normally distributed data were analyzed with the test. If data were not distributed normally, the Wilcoxon rank-sum test was used, and for categorical variables the $\chi^{2}$ test was applied. Univariate regression was used to investigate relationships between AHI (dependent variable) and possible determinants. Further multivariate analysis involved regression of variables that showed a univariate $\mathrm{p}$ value $<0.1$. A $\mathrm{p}$ value $<0.05$ was considered to indicate statistical significance. 


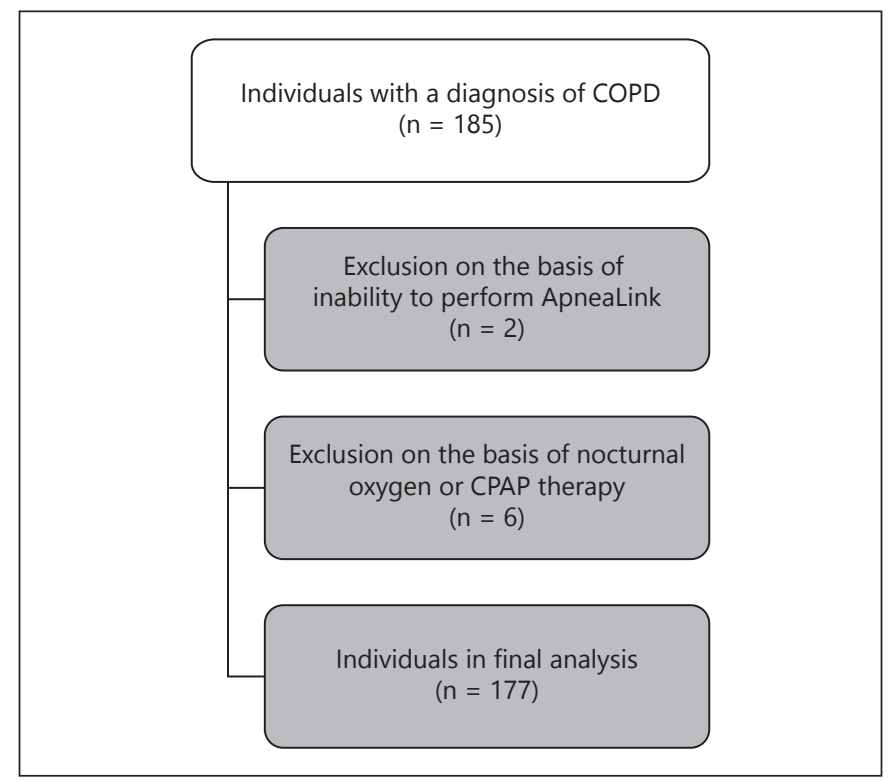

Fig. 1. Study flow diagram. $\mathrm{CPAP}=$ Continuous positive airway pressure.

\section{Results}

\section{Characteristics of the Study Population}

We recruited 185 patients with diagnosed COPD. From these, 6 were excluded on the basis of nocturnal treatment with continuous positive airway pressure or oxygen therapy, and thus no possibility to perform the requested nocturnal sleep studies. A further 2 participants had to be excluded on the basis of inability to perform a valid ApneaLink measurement (fig. 1). A total of 177 individuals were included in the final analyses. The patient characteristics are presented in detail in table 1.

Thirty-five participants (19.8\%) had an ESS $>10$ and were considered sleepy. Sixty-one subjects (35\%) had an AHI of $>5$ events per hour and 33 patients (19\%) had an AHI of $>10$, and thus were considered to have OSA (fig. 2). Comparing characteristics between the group with an AHI $\leq 10$ events per hour and the group with an AHI $>10$ events per hour, individuals with evidence for the overlap syndrome presented with higher BMI, higher $\mathrm{FEV}_{1}$ and less frequent exacerbations (table 2; online suppl. table, for all online suppl. material, see www.karger. com/doi/10.1159/000368615).

Significantly higher rates of arterial hypertension and diabetes mellitus were found in the group of COPD patients with evidence for OSA. Cardiovascular disease was not found to be more frequent in the patients with the overlap syndrome compared to patients with COPD

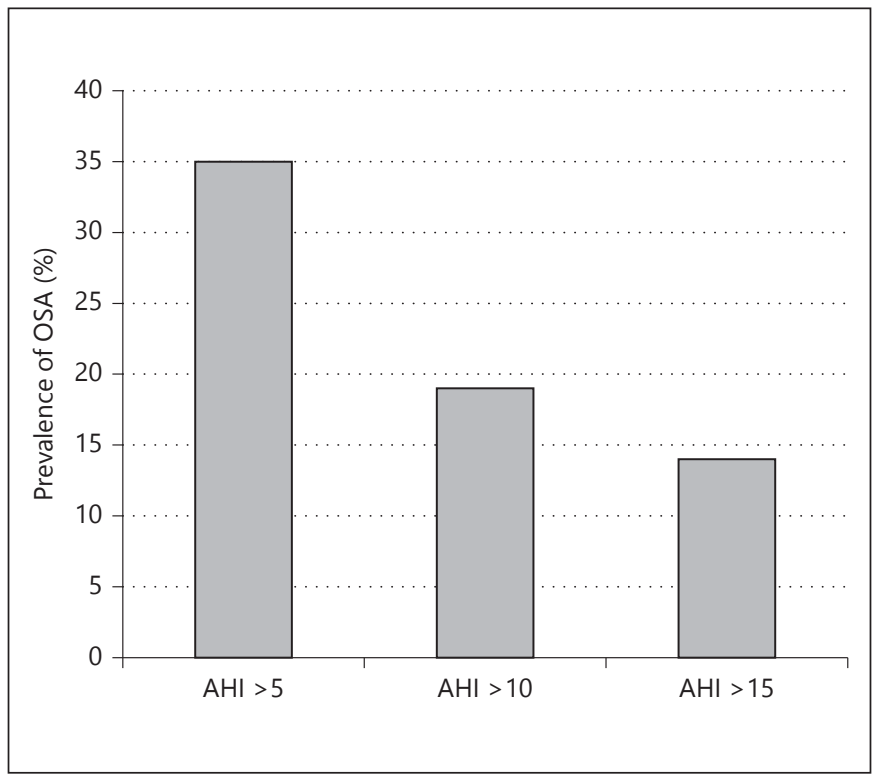

Fig. 2. Prevalence of OSA in the COPD cohort using different AHI events per hour thresholds.

Table 1. Characteristics of the study population

\begin{tabular}{|c|c|}
\hline Characteristics & Patients $(n=177)$ \\
\hline Age, years & $63.8(8.8)$ \\
\hline Male/female, $\mathrm{n}$ & $112 / 65$ \\
\hline $\mathrm{BMI}, \mathrm{kg} / \mathrm{m}^{2}$ & $25.4(21.8 / 29.5)$ \\
\hline Systolic blood pressure, $\mathrm{mm} \mathrm{Hg}$ & $126.5(116 / 141)$ \\
\hline Current smoker, $\mathrm{n}$ & $61(35)$ \\
\hline Pack years & $40(24.2 / 60)$ \\
\hline CAT score & $15.5(10 / 21)$ \\
\hline Exacerbations per year, $\mathrm{n}$ & $0(0 / 1)$ \\
\hline $\mathrm{SpO}_{2}$ daytime, $\%$ & $95(93 / 96)$ \\
\hline $\mathrm{FEV}_{1} \%$ pred & $57(32 / 75.7)$ \\
\hline GOLD stage $1, \mathrm{n}$ & $25(14)$ \\
\hline GOLD stage $2, \mathrm{n}$ & $72(41)$ \\
\hline GOLD stage $3, \mathrm{n}$ & $38(22)$ \\
\hline GOLD stage $4, \mathrm{n}$ & $42(24)$ \\
\hline AHI, events/h & $4(1 / 8)$ \\
\hline ODI, events/h & $4(2 / 8)$ \\
\hline Mean nocturnal $\mathrm{SpO}_{2}, \%$ & $92(90 / 94)$ \\
\hline ESS score & $6(4 / 10)$ \\
\hline Arterial hypertension, $\mathrm{n}$ & $74(42)$ \\
\hline Cardiovascular disease, $\mathrm{n}$ & $24(14)$ \\
\hline Diabetes mellitus, $\mathrm{n}$ & $25(17)$ \\
\hline LAMA, $\mathrm{n}$ & $11(6)$ \\
\hline $\mathrm{LABA}+\mathrm{GC}, \mathrm{n}$ & $23(13)$ \\
\hline $\mathrm{LAMA}+\mathrm{LABA}+\mathrm{GC}, \mathrm{n}$ & $77(44)$ \\
\hline
\end{tabular}

Age is presented as the mean with SD in parentheses; other values are $\mathrm{n}$ with percentage in parentheses, or median with percentiles in parentheses. ODI = Oxygen desaturation index; LAMA = long-acting muscarinicantagonist; LABA = long-acting $\beta$-agonist; $\mathrm{GC}=$ glucocorticosteroid . 
Table 2. Characteristics according to evidence for OSA

\begin{tabular}{|c|c|c|c|}
\hline Characteristics & $\begin{array}{l}\mathrm{AHI} \leq 10 \\
(\mathrm{n}=144)\end{array}$ & $\begin{array}{l}\text { AHI > } 10 \\
(n=33)\end{array}$ & $\mathrm{p}$ value \\
\hline Age, years & $63.2(8.6)$ & $65.6(9.6)$ & 0.152 \\
\hline Male, $\mathrm{n}$ & $83(58)$ & $29(88)$ & 0.001 \\
\hline BMI, $\mathrm{kg} / \mathrm{m}^{2}$ & $24.2(21.1 / 28.4)$ & $30.0(26.9 / 36.3)$ & $<0.001$ \\
\hline Systolic blood pressure, $\mathrm{mm} \mathrm{Hg}$ & $126(115 / 140)$ & $129(119 / 141)$ & 0.597 \\
\hline Current smoker, $\mathrm{n}$ & $54(38)$ & $7(21)$ & 0.076 \\
\hline Pack years & $40(24 / 53)$ & $40(28 / 60)$ & 0.326 \\
\hline ESS score & $6(4 / 9)$ & $7(4 / 11)$ & 0.148 \\
\hline CAT score & $16.5(10.0 / 21.0)$ & $14.0(9.0 / 21.0)$ & 0.418 \\
\hline $\mathrm{FEV}_{1} \%$ pred & $50.4(31.0 / 74.3)$ & $71.2(55.5 / 77.5)$ & 0.007 \\
\hline $\mathrm{SpO}_{2}$ daytime, $\%$ & $95(93 / 96)$ & $95(93 / 96)$ & 0.565 \\
\hline GOLD stage & $2.6(1.0)$ & $2.2(0.9)$ & 0.012 \\
\hline Exacerbations per year, $\mathrm{n}$ & $0(0 / 1)$ & $0(0 / 0)$ & 0.004 \\
\hline ODI, events/h & $3(1 / 6)$ & $21(13 / 35)$ & $<0.001$ \\
\hline AHI, events/h & $2(1 / 5)$ & $20(15 / 37)$ & $<0.001$ \\
\hline Mean nocturnal $\mathrm{SpO}_{2}, \%$ & $92.5(90.0 / 94.0)$ & $91.0(89.0 / 93.0)$ & 0.070 \\
\hline Time spent at $\mathrm{SpO}_{2}<90 \%$, min & $38(8 / 184)$ & $147(22 / 291)$ & 0.016 \\
\hline Arterial hypertension, $\mathrm{n}$ & $54(38)$ & $20(61)$ & 0.015 \\
\hline Cardiovascular disease, $\mathrm{n}$ & $18(13)$ & $6(18)$ & 0.390 \\
\hline Diabetes mellitus, $\mathrm{n}$ & $14(10)$ & $11(33)$ & $<0.001$ \\
\hline LAMA, $\mathrm{n}$ & $8(5)$ & $3(9)$ & 0.448 \\
\hline $\mathrm{LABA}+\mathrm{GC}, \mathrm{n}$ & $19(13)$ & $4(12)$ & 0.869 \\
\hline $\mathrm{LAMA}+\mathrm{LABA}+\mathrm{GC}, \mathrm{n}$ & $68(47)$ & $9(27)$ & 0.037 \\
\hline
\end{tabular}

Age and GOLD stage are presented as the mean with SD in parentheses; other values are $\mathrm{n}$ with percentage in parentheses, or median with percentiles in parentheses. ODI = Oxygen desaturation index; LAMA = longacting muscarinic-antagonist; LABA = long-acting beta-agonist; GC = glucocorticosteroid.

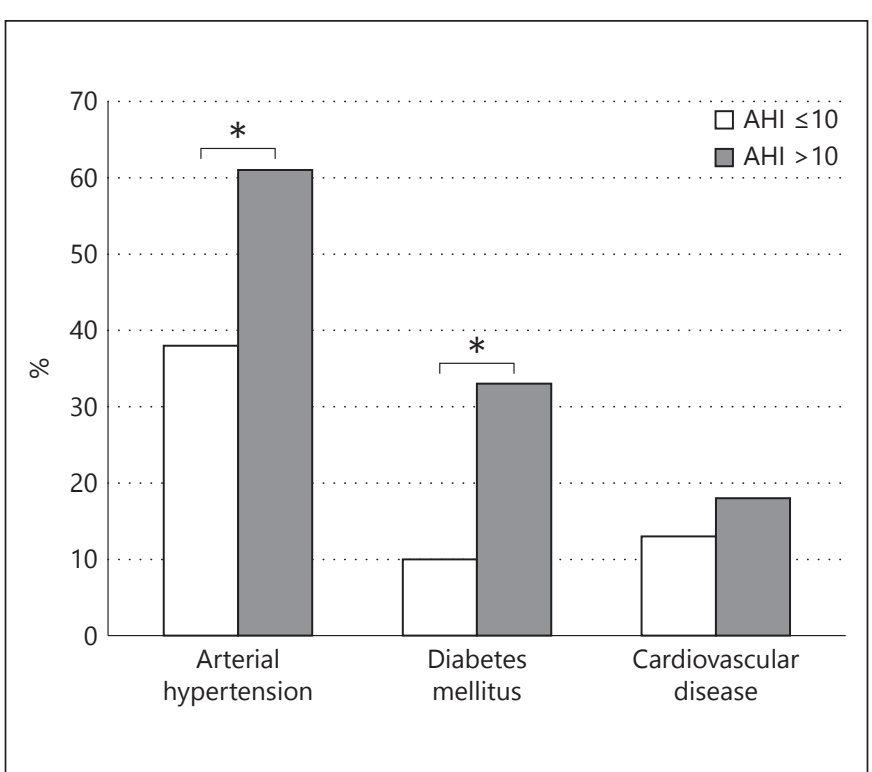

Fig. 3. Comorbidities in COPD with and without evidence for OSA. AHI thresholds represent events per hour. ${ }^{*} \mathrm{p}<0.05$. alone (fig. 3). In a univariate analysis, male sex, BMI, pack years, daytime peripheral oxygen saturation $\left(\mathrm{SpO}_{2}\right)$, exacerbation rate, mean nocturnal $\mathrm{SpO}_{2}$ and diabetes mellitus were significantly associated with AHI (table 3 ).

In multiple regression analysis, including age, gender, BMI, pack years, ESS, daytime $\mathrm{SpO}_{2}$ exacerbation frequency, mean nocturnal $\mathrm{SpO}_{2}$ and diabetes mellitus as independent variables and with $\mathrm{AHI}$ as the dependent variable, only BMI and pack years were found to be significantly associated with AHI. The ESS was not significantly associated with AHI (table 4). Due to the interrelationship between mean nocturnal $\mathrm{SpO}_{2}$ and time spent at $\mathrm{SpO}_{2}<90 \%(\mathrm{r}=-0.78, \mathrm{p}<0.001)$, the latter was removed from the final model.

\section{Discussion}

This study evaluated the prevalence, possible predictors and associated comorbidities of the overlap syndrome in a typical but heterogeneous group of COPD 
Table 3. Univariate regression analysis of factors possibly associated with AHI

\begin{tabular}{|c|c|c|c|}
\hline Characteristics & B & $95 \% \mathrm{CI}$ & $\mathrm{p}$ value \\
\hline Age & 0.05 & $-0.19 / 0.28$ & 0.701 \\
\hline Male & 5.90 & $1.73 / 10.06$ & 0.006 \\
\hline BMI & 1.18 & $0.88 / 1.48$ & $<0.001$ \\
\hline Systolic blood pressure & 0.07 & $-0.04 / 0.17$ & 0.215 \\
\hline Current smoker & -3.41 & $-7.70 / 0.88$ & 0.119 \\
\hline Pack years & 0.11 & $0.03 / 0.18$ & 0.005 \\
\hline ESS score & 0.42 & $-0.06 / 0.91$ & 0.088 \\
\hline CAT score & -0.07 & $-0.35 / 0.20$ & 0.598 \\
\hline $\mathrm{FEV}_{1} \%$ pred & 0.05 & $-0.04 / 0.13$ & 0.265 \\
\hline $\mathrm{SpO}_{2}$ daytime & -0.83 & $-1.51 /-0.15$ & 0.017 \\
\hline GOLD stage & -1.00 & $-3.05 / 1.04$ & 0.335 \\
\hline Exacerbations per year & -1.42 & $-2.80 /-0.05$ & 0.042 \\
\hline Mean nocturnal $\mathrm{SpO}_{2}$ & -0.96 & $-1.57 /-0.36$ & 0.002 \\
\hline Time spent at $\mathrm{SpO}_{2}<90 \%$ & 0.01 & $-0.00 / 0.02$ & 0.057 \\
\hline Cardiovascular disease & 2.77 & $-3.22 / 8.75$ & 0.362 \\
\hline Diabetes mellitus & 11.11 & $5.45 / 16.77$ & $<0.001$ \\
\hline LAMA & 4.63 & $-3.85 / 13.11$ & 0.283 \\
\hline $\mathrm{LABA}+\mathrm{GC}$ & -0.43 & $-6.53 / 5.68$ & 0.891 \\
\hline $\mathrm{LAMA}+\mathrm{LABA}+\mathrm{GC}$ & -1.88 & $-6.01 / 2.25$ & 0.371 \\
\hline
\end{tabular}

LAMA = Long-acting muscarinic-antagonist; LABA = longacting $\beta$-agonist; $\mathrm{GC}=$ glucocorticosteroid.

Table 4. Multiple regression analysis with AHI as the dependent variable

\begin{tabular}{lrrr}
\hline Characteristics & \multicolumn{1}{l}{ B } & \multicolumn{1}{l}{$95 \% \mathrm{CI}$} & p value \\
\hline Male/female & 1.57 & $-2.30 / 5.44$ & 0.423 \\
$\mathrm{BMI}$ & 0.93 & $0.59 / 1.27$ & $<0.001$ \\
Pack years & 0.08 & $0.01 / 0.15$ & 0.022 \\
$\mathrm{ESS}_{\text {score }}$ & 0.05 & $-0.39 / 0.49$ & 0.815 \\
$\mathrm{SpO}_{2}$ daytime & -0.70 & $-1.45 / 0.05$ & 0.067 \\
Exacerbations per year & -0.86 & $-2.05 / 0.33$ & 0.154 \\
Mean nocturnal SpO $_{2}$ & -0.10 & $-0.80 / 0.60$ & 0.775 \\
Cardiovascular disease $_{\text {Diabetes mellitus }}^{-3.22}$ & $-8.51 / 2.08$ & 0.232 \\
& 4.57 & $-0.89 / 10.04$ & 0.100 \\
\hline
\end{tabular}

patients. We found a prevalence of OSA of almost 20\% using a threshold of AHI $>10$ events per hour. BMI and pack years were the only significant predictors for OSA in the current study. Arterial hypertension and diabetes mellitus were more frequent in patients with the overlap syndrome.

The prevalence of the overlap syndrome in our cohort was almost $20 \%$. In the middle-aged general population the prevalence of OSA with only mild symptoms may be up to $30 \%[8,9]$. The prevalence of OSA in COPD, the overlap syndrome, has not yet been defined and varies dependent on the studied population. In OSA patients, a high prevalence of COPD ranging from $11[10,11]$ up to $41 \%[12]$ has been reported. In COPD on the other hand, while some studies found a higher prevalence of OSA in patients with COPD compared to subjects without COPD [13], other studies, such as Sanders et al. [11], found a prevalence of OSA similar to the one described in the general population. Sanders et al. [11] analyzed data of a prospective multicenter cohort study in which 5,954 patients with and without obstructive airway disease were examined. A prevalence of OSA (respiratory disturbance index $>10$ events per hour) of $22.3 \%$ was found in patients with obstructive airway disease. The reported prevalence of OSA in patients with obstructive airway disease in the latter study is comparable to the prevalence of $19 \%$ (AHI $>10)$ that we found.

In the multiple regression analysis, BMI and pack years were the only predictors for OSA. Our findings are in line with previous studies which found a positive association between AHI and BMI [20,21]. As patients in higher COPD GOLD stages also had a lower BMI, possibly reflecting the systemic effects of this chronic disease, we assume that lower BMI was the cause of the lower AHI in patients with more severe COPD, since GOLD stages, $\mathrm{FEV}_{1}$ and daytime $\mathrm{SpO}_{2}$ were not independent predictors for AHI in the multivariate analysis. Generally, a weight reduction has been shown to lead to a reduction in AHI [22].

There are previous studies investigating the influence of smoking on OSA. In an observational study comparing 108 patients with and 106 patients without OSA, Kashyap et al. [23] found a significantly higher prevalence of active smokers in OSA patients compared to patients without OSA (35 vs. 18\%). Furthermore, current smokers had a 2.8 -fold higher risk of OSA compared to nonsmokers. In contrast, a cross-sectional study with 3,509 sleep-disorder patients by Hoffstein [24] investigating the relationship between smoking and OSA did not show an independent association between the two. Furthermore, there was no independent association found between pack years and AHI in the latter study. However, these findings are difficult to compare with our findings since there are no studies investigating the influence of pack years on AHI in COPD patients. Therefore, further studies are needed to examine the influence of active smoking on OSA in COPD. 
In daily practice, daytime sleepiness is commonly assessed by the ESS [17]. We evaluated ESS but did not choose to add pathologic ESS in the diagnostic criteria for OSA. Abnormal daytime sleepiness assessed by the ESS was found in $20 \%$ of our study population, but only $8 \%$ of the participants had both an elevated ESS and AHI, thus indicating poor correlation between the two measures and implying that the ESS cannot be used to identify COPD patients with possible OSA.

The pathophysiological background and cause of the overlap syndrome is not known. In our study, a prevalence of almost $20 \%$ of the overlap syndrome was found, prompting the assumption that COPD and OSA may be linked by common mechanisms. In patients with overlap syndrome, the mortality due to cardiovascular events has been shown to be higher in comparison to one single disease alone [25]. Some preliminary evidence that both diseases may lead to systemic inflammation [26], and accelerate atherosclerosis $[27,28]$ and vascular dysfunction $[29,30]$, and thus might increase comorbidities such as arterial hypertension [31], have been presented before. This is in line with our findings that those with the overlap syndrome had a higher rate of arterial hypertension and diabetes.

The present study has some limitations. As it was an observational study we have to rely on the information given by the patients concerning ESS and CAT, exacerbation rate, smoking history, medication use and comorbidities. As a cross-sectional study evaluates one time point only, no conclusion can be made in our study regarding the causal relationship between COPD and OSA. When interpreting a sleep study, the chosen device for examination is of importance. In previous studies the
ApneaLink has been shown to underestimate the AHI score in subjects with severe OSA, and slightly overestimate AHI in patients with very mild OSA [32]. However, the addition of oximetry data (oxygen desaturation index) showed an improvement of the specificity, reducing false positive results [19]. Further unattended polysomnography in an outpatient setting has been applied in previous studies $[13,11]$ and it has been shown to be cost-effective and convenient for the patient, providing validated and highly sensitive and specific results not inferior to those collected by laboratory polysomnography [33-35].

In this study, only excessive sleepiness (ESS) was considered as a possible clinical predictor for OSA in addition to anthropometric data and comorbidities. Further studies will need to investigate the usefulness of other possible clinical predictors for OSA in patients with COPD, such as a history of snoring or witnessed apneas.

In conclusion, the present observational study in a Swiss cohort of COPD patients showed a prevalence of OSA of almost $20 \%$. BMI and pack years were the only clinical predictors for OSA in our cohort, while ESS cannot be used to identify COPD patients with OSA. Comorbidities such as arterial hypertension and diabetes were found more often in patients with the overlap syndrome compared to patients with COPD alone, possibly providing an explanation for the high mortality found in these patients.

\section{Acknowledgement}

The authors would like to acknowledge that this research project was kindly supported by the University Basel Research fund.

\section{References}

1 Vestbo J, Hurd SS, Agusti AG, Jones PW, Vogelmeier C, Anyueto A, Barnes PJ, Fabbri LM, Martinez FJ, Nishimura M, Stocklez RA, Sin DD, Rodriguez-Roisin R: Global strategy for the diagnosis, management and prevention of chronic obstructive pulmonary disease: GOLD executive summary. Am J Respir Crit Care Med 2013;187:347-365.

2 Ford ES, Wheaton AG, Mannino DM, Presley-Cantrell L, Li C, Croft JB: Elevated cardiovascular risk among adults with obstructive and restrictive airway functioning in the United States: a cross-sectional study of the National Health and Nutrition Examination Survey from 2007-2010. Respir Res 2012;13: 115.

3 Flenley DC: Sleep in chronic obstructive lung disease. Clin Chest Med 1985;6:651-661.
4 Owens RL, Malhotra A: Sleep-disordered breathing and COPD: the overlap syndrome. Respir Care 2010;55:1333-1346.

5 Epstein LJ, Kristo D, Strollo PJ, et al: Clinical guideline for the evaluation, management and long-term care of obstructive sleep apnea in adults. J Clin Sleep Med 2009;5:263276.

6 Buist AS, McBurnie MA, Vollmer WM, Gillespie S, Burney P, Mannino DM, Menezes AM, Sullivan SD, Lee TA, Weiss KB, Jensen RL, Marks GB, Gulsvik A, Nizankowska-Mogilnicka E; BOLD Collaborative Research Group: International variation in the prevalence of COPD (the BOLD Study): a population-based prevalence study. Lancet 2007; 370:741-750.
7 Menezes AM, Perez-Padilla R, Jardim JR, et al: Chronic obstructive pulmonary disease in five Latin American cities (the PLATINO study): a prevalence study. Lancet 2005;366: 1875-1881.

8 American Academy of Sleep Medicine: ICSD2 - International Classification of Sleep Disorders, ed 2. Westchester, American Academy of Sleep Medicine, 2005.

9 Young T, Palta M, Dempsey J, Skatrud J, Weber S, Badr S: The occurrence of sleep-disordered breathing among middle-aged adults. N Engl J Med 1993;328:1230-1235.

10 Chaouat A, Weitzenblum E, Krieger J, Ifoundza T, Oswald M, Kessler K: Association of chronic obstructive pulmonary disease and sleep apnea syndrome. Am J Respir Crit Care Med 1995;151:82-86. 
11 Sanders $M H$, Newman AB, Haggerty CL, Redline S, Lebowitz M, Samet J, O'Connor GT, Punjabi NM, Shahar E; Sleep Heart Health Study: Sleep and sleep-disordered breathing in adults with predominantly mild obstructive airway disease. Am J Respir Crit Care Med 2003;167:7-14.

12 O'Brien A, Whitman K: Lack of benefit of continuous positive airway pressure on lung function in patients with overlap syndrome. Lung 2005;183:389-404.

13 Larsson LG, Lindberg A, Franklin KA, Lundbäck B: Obstructive sleep apnoea syndrome in common subjects with chronic bronchitis. Respiration 2001;68:250-255.

14 Marin JM, Soriano JB, Carrizo SJ, Boldova A, Celli BR: Outcomes in patients with chronic obstructive pulmonary disease and obstructive sleep apnea: the overlap syndrome. Am J Respir Crit Care Med 2010;182:325-331.

15 Global Initiative for Chronic Obstructive Lung Disease: The global strategy for the diagnosis, management and prevention of COPD. http://www.goldcopd.org/.

16 Burge S, Wedzicha JA: COPD exacerbations: definitions and classifications. Eur Respir J Suppl 2003;41:46S-53S.

17 Bloch KE, Schoch OD, Zhang JN, Russi EW: German version of the Epworth Sleepiness Scale. Respiration 1999;66:440-447.

18 Jones PW, Harding G, Berry P, Wiklund I, Chen WH, Kline Leidy N: Development and first validation of the COPD Assessment Test. Eur Respir J 2009;34:648-654.

19 Nigro CA, Dibur E, Malnis S, Grandval S, Nogueira F: Validation of ApneaLink $\mathrm{Ox}^{\mathrm{TM}}$ for the diagnosis of obstructive sleep apnea. Sleep Breath 2013;17:259-266.
20 Bixler EO, Vgontzas AN, Ten Have T, Tyson $\mathrm{K}$, Kales A: Effects of age on sleep apnea in men. I. Prevalence and severity. Am J Respir Crit Care Med 1998;157:144-148.

21 Bixler EO, Vgontzas AN, Lin HM, Ten Have T, Rein J, Vela-Bueno A, Kales A: Prevalence of sleep-disordered breathing in women: effects of gender. Am J Respir Crit Care Med 2001;163:608-613.

22 Kuna ST, Reboussin DM, Borradaile KE Long-term effect of weight loss on obstructive sleep apnea severity in obese patients with type 2 diabetes. Sleep 2013;36:641A-649A.

23 Kashyap R, Hock LM, Bowman TJ: Higher prevalence of smoking in patients diagnosed as having obstructive sleep apnea. Sleep Breath 2001;5:167-172.

24 Hoffstein V: Relationship between smoking and sleep apnea in clinic population. Sleep 2002;25:519-524.

25 Machado M-CL, Vollmer WM, Togeiro SM, Bilderback AL, Oliveira M-VC, Leitao FS, Queiroga F Jr, Lorenzi-Filho G, Krishnan JA: $\mathrm{CPAP}$ and survival in moderate-to-severe obstructive sleep apnoea syndrome and hypoxaemic COPD. Eur Respir J 2010;35:132-137.

26 Nural S, Günay E, Halici B, Celik S, Ünlü M: Inflammatory processes and effects of continuous positive airway pressure (CPAP) in overlap syndrome. Inflammation 2013;36: 66-74.

27 Tsuda H, Moritsuchi Y, Almeida FR, Lowe AA, Tsuda T: The relationship between cephalometric carotid artery calcification and Framingham Risk Score profile in patients with obstructive sleep apnea. Sleep Breath 2013;17:1003-1008.

28 Shiina K, Tomiyama H, Takata Y, Yoshida M, Kato K, Nishihata Y, Matsumoto C, Odaira M, Saruhara H, Hashimura Y, Usui Y, Yamashina A: Overlap syndrome: additive effects of COPD on the cardiovascular damages in patients with OSA. Respir Med 2012;106: 1335-1341.
29 Kohler M, Stradling JR: Mechanisms of vascular damage in obstructive sleep apnea. Nat Rev Cardiol 2010;7:677-685.

30 van Gestel AJ, Kohler M, Clarenbach CF: Sympathetic overactivity and cardiovascular disease in patients with chronic obstructive pulmonary disease (COPD). Discov Med 2012;14:359-368.

31 Bixler EO, Vgontzas AN, Lin HM, Ten Have T, Leiby BE, Vela-Bueno A, Kales A: Association of hypertension and sleep-disordered breathing. Arch Intern Med 2000;160:22892295.

32 Ermann MK, Stewart D, Einhorn D, Gordon $\mathrm{N}$, Casal E: Validation of the ApneaLink for the Screening of sleep apnea: a novel and simple single-channel recording device. J Clin Sleep Med 2007;3:387-392.

33 Ng SSS, Chan TO, To KW, Ngai J, Tung A, Ko FWS, Hui DSC: Validation of a portable recording device (ApneaLink) for identifying patients with suspected obstructive sleep apnoea syndrome. Int Med J 2009;39:757-762.

34 Kuna ST, Gurubhagavatula I, Maislin G, Hin S, Hartwig KC, McCloskey S, Hachadoorian R, Hurley S, Gupta R, Staley B, Atwood CW: Noninferiority of functional outcome in ambulatory management of obstructive sleep apnea. Am J Respir Crit Care Med 2011;183: 1238-1244.

35 Rosen CL, Auckley D, Benca R, FoldvarySchaefer N, Iber C, Kapur V, Rueschman M, Zee P, Redline S: A multisite randomized trial of portable sleep studies and positive airway pressure autotitration versus laboratorybased polysomnography for the diagnosis and treatment of obstructive sleep apnea: the HomePAP study. Sleep 2012;35:757-767. 